\title{
Temazepam Measurement
}

National Cancer Institute

\section{Source}

National Cancer Institute. Temazepam Measurement. NCI Thesaurus. Code C75376.

The determination of the amount of temazepam present in a sample. 